\title{
Economic evaluation of HIV pre-exposure prophylaxis among men-who-have-sex-with-men in England in 2016
}

Koh Jun Ong ${ }^{1}$, Sarika Desai ${ }^{1}$, Nigel Field ${ }^{2}$, Monica Desai ${ }^{1}$, Anthony Nardone ${ }^{1}$, Albert Jan van Hoek ${ }^{3}$, Owen Noel Gill ${ }^{1}$

1. HIV \& STI Department, National Centre for Infectious Disease Surveillance and Control (CIDSC), Public Health England, London, United Kingdom

2. Research Department of Infection \& Population Health, University College London, London, United Kingdom

3. London School of Hygiene \& Tropical Medicine, London, United Kingdom

Correspondence: Koh Jun Ong (kohjun.ong@phe.gov.uk)

Citation style for this article:

Ong Koh Jun, Desai Sarika, Field Nigel, Desai Monica, Nardone Anthony, van Hoek Albert Jan, Gill Owen Noel. Economic evaluation of HIV pre-exposure prophylaxis among men-who-have-sex-with-men in England in 2016. Euro Surveill. 2017;22(42):pii=17-00192. https://doi.org/10.2807/1560-7917.ES.2017.22.42.17-00192

Article submitted on 13 Mar 2017 / accepted on 15 Aug 2017 / published on 19 Oct 2017

Clinical effectiveness of pre-exposure prophylaxis (PrEP) for preventing HIV acquisition in men who have sex with men (MSM) at high HIV risk is established. A static decision analytical model was constructed to inform policy prioritisation in England around cost-effectiveness and budgetary impact of a PrEP programme covering 5,000 MSM during an initial highrisk period. National genitourinary medicine clinic surveillance data informed key HIV risk assumptions. Pragmatic large-scale implementation scenarios were explored. At $86 \%$ effectiveness, PrEP given to 5,000 MSM at 3.3 per 100 person-years annual HIV incidence, assuming risk compensation (20\% HIV incidence increase), averted 118 HIV infections over remaining lifetimes and was cost saving. Lower effectiveness $(64 \%)$ gave an incremental cost-effectiveness ratio of + GBP 23,500 (EUR 32,000) per quality-adjusted life year (QALY) gained. Investment of GBP 26.9 million (EUR 36.6 million) in year-1 breaks even anywhere from year-23 (86\% effectiveness) to year-33 (64\% effectiveness). PrEP cost-effectiveness was highly sensitive to year-1 HIV incidence, PrEP adherence/ effectiveness, and antiretroviral drug costs. There is much uncertainty around HIV incidence in those given PrEP and adherence/effectiveness, especially under programme scale-up. Substantially reduced PrEP drug costs are needed to give the necessary assurance of cost-effectiveness, and for an affordable public health programme of sufficient size.

\section{Introduction}

In the United Kingdom (UK) new prevention initiatives are needed to reduce the estimated 2,800 incident HIV infections occurring annually in men who have sex with men (MSM) [1]. The UK PROUD study demonstrated that HIV pre-exposure prophylaxis (PrEP) with daily oral antiretroviral (ARV) drug combination tenofovir disoproxil and emtricitabine in addition to standard-of-care risk reduction for MSM at high HIV risk, reduced HIV incidence over the participant follow-up period by $86 \%$
(90\% confidence interval (Cl): 64-96\%) [2]. The PROUD data on PrEP effectiveness, supported by the placebocontrolled efficacy data from iPrEX and IPERGAY, showed that PrEP offers a major opportunity to reduce HIV incidence in MSM [3,4]. A PrEP policy was proposed by National Health Service (NHS) England for high HIV risk attendees of the 215 genitourinary medicine (GUM) clinics in England that provide free, confidential, openaccess sexual health services [5].

In England, new clinical commissioning policies are prioritised on their effectiveness and value for money [6]. Cost-effectiveness evidence is reviewed, with incremental value for money of competing services scored and compared on the basis of their incremental costs and incremental benefits. In other areas of publically funded public health prevention programmes (e.g. immunisation), one decision criterion used is a high certainty that the incremental cost-effectiveness ratio (ICER) falls below a recommended threshold, currently GBP 20,000 (EUR 27,210) per quality-adjusted life year (QALY) gained $[7,8]$. In addition, the affordability of any new service must be ensured based on practical eligibility criteria that are developed to guarantee the service reaches those with greatest need [6].

A static decision analytical model was used to explore the economic implications of a first phase scale-up of a PrEP programme for MSM GUM clinic attendees at high HIV risk, beginning in 2016. The method is valid for a modest scale initial PrEP programme with limited indirect (herd) effect [9], and was chosen for the relatively limited assumptions required, its transparency and ease of interpretation for decision makers, and because of the increasing uncertainties when estimating costs and effects after 5 to 10 years. Moreover, the technique was suitable because the impact on population disease dynamics is likely to be limited in the early years of a PrEP policy given the small numbers protected relative to the total at risk [9]. 


\section{FIGURE 1}

Decision analytical model structure comparing no-PrEP with PrEP in 5,000 men who have sex with men at high HIV riska, England, 2016

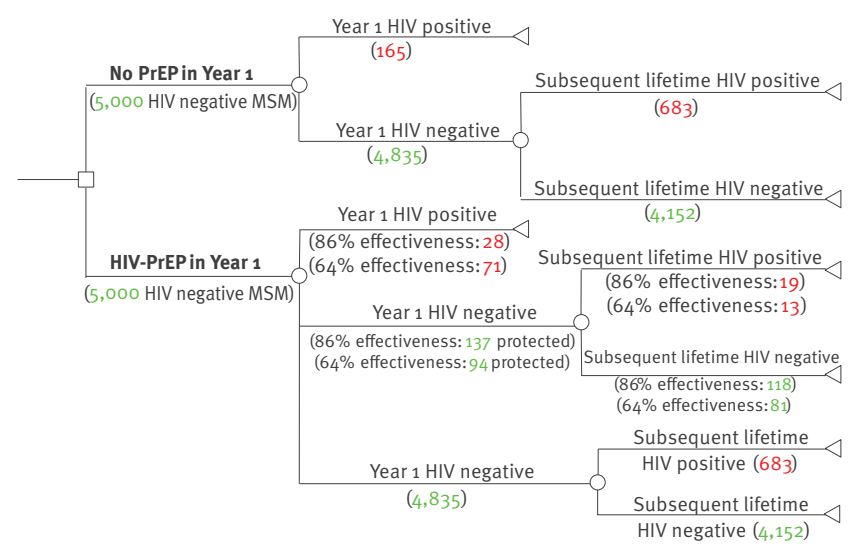

MSM: men who have sex with men; PrEP: pre-exposure prophylaxis.

Red and green colours are used to indicate the estimated numbers of HIV-positive or negative MSM respectively, after a defined period (i.e. after the first year of PrEP (year-1) or, for the control group, after year-1 without PrEP, and for the remaining lifetime in both groups).

${ }^{a}$ HIV incidence in Year-1 is 3.3 per 100 person-years and cumulative lifetime incidence without PrEP is $16.96 \%$.

\section{Methods}

The perspective of a healthcare provider was taken. A 5,000 person-years PrEP coverage level was judged to be reasonable for this initial scale-up period, based on the range suggested by a multidisciplinary, multistakeholder group of clinicians, patients, commissioners (budget holders) and public health practitioners [5]. The 4,500-6,500 range was generated after considering the evidence around likely programme roll-out scenarios, the GUM clinic activity dataset (GUMCAD) estimated need, patient-level uptake as informed by community surveys about willingness to take PrEP, and considered potential organisational challenges of delivery across many GUM clinics as well as evidence of PrEP scale-up in other countries [10].

The lifetime HIV risk of 5,000 MSM who began an initial high HIV risk period of one year on PrEP was compared with the lifetime risk of the same group in the absence of PrEP (Figure 1). This required age distribution of MSM at high behavioural risk and estimates of HIV acquisition during the high-risk period of PrEP eligibility, as well as estimates of lifetime HIV acquisition, to account for the residual HIV risk after the high-risk period had passed. PrEP provision to a single high-risk year was modelled at the cohort-level. At the individual-level, should high risk continue beyond the first year, then that individual will form part of a new high-risk cohort in the second year. The ICER for PrEP remains the same for the second cohort as for the previous year's highrisk cohort.

\section{FIGURE 2}

Impact of year-1 PrEPa on HIV incidence over 10 years for 5,000 MSM at initial high HIV risk, England, 2016-2025

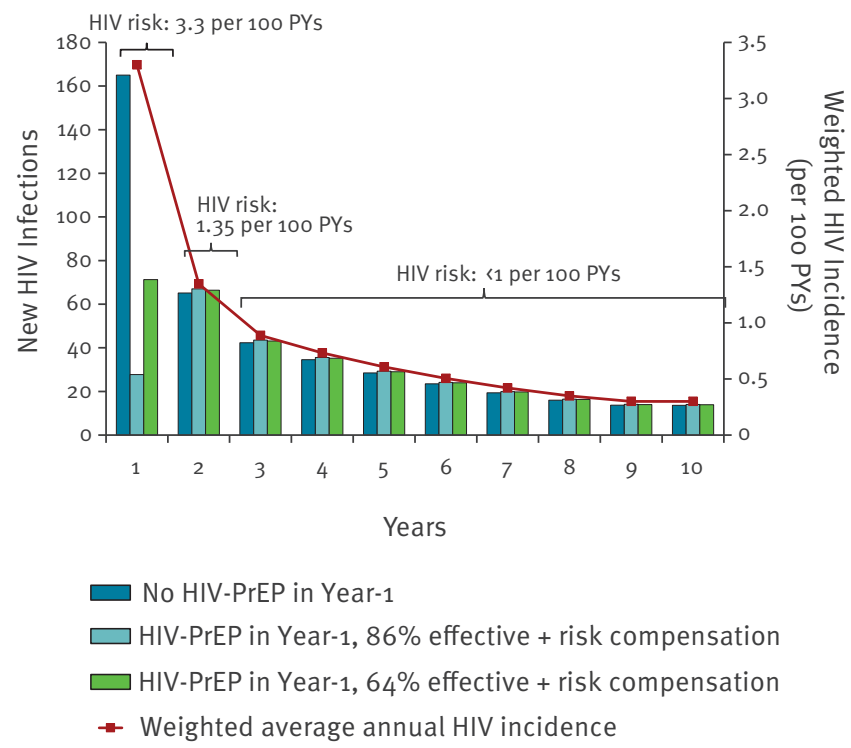

PrEP: pre-exposure prophylaxis; PYs: person-years.

The bars on this chart represent the number of new HIV infections by year: (i) In the absence of PrEP (blue bars); (ii) If PrEP is given in year- 1 and assuming $86 \%$ effectiveness + risk compensation (turquoise bars); (iii) and if PrEP is given in year-1 and assuming $64 \%$ effectiveness + risk compensation (green bars).

Up to age 75 years, there were 848 HIV infections without PrEP, and 730 with PrEP at $86 \%$ effectiveness and 767 with PrEP at $64 \%$ effectiveness. Slightly more later-HIV infections occur in those given PrEP during year-1 as the MSM protected by PrEP become susceptible on stopping PrEP, albeit at a much lower risk level.

a PrEP effectiveness at either $86 \%$ or $64 \%$, both with risk compensation adjustment (see text).

Data were extracted from GUMCAD [11], a comprehensive, pseudo-anonymised digital download of patientlevel data on all sexually transmitted infection (STI) services and diagnoses provided in GUM clinics in England. Each pseudo-anonymised record contains a clinic identifier as well as a local patient number, so data from the same individual attending the same clinic can be linked longitudinally. Estimates of lifetime HIV risk were adjusted to the age-distribution of MSM GUM clinic attendees, using averages for years 201314 (see supplementary material [12]).

In the principal scenarios, MSM receiving PrEP were assumed to be prescribed daily tenofovir disoproxil and emtricitabine combined tablet, in accordance with the European Medicines Agency licensed prevention indication [13]. Event-based dosing (i.e. PrEP given before and after sexual exposure) for an average of four tablets used per 7-day period, was explored in sensitivity analyses [4]. 


\section{FIGURE 3}

Multivariate sensitivity of incremental cost-effectiveness ratio (ICER) for different levels of pre-exposure prophylaxis (PrEP) effectiveness, England, 2014/15 cost values

\begin{tabular}{|c|c|c|c|c|c|}
\hline \multirow{2}{*}{\multicolumn{2}{|c|}{ Parameter combinations ${ }^{a}$}} & \multicolumn{4}{|c|}{ PrEP effectiveness ${ }^{b}$} \\
\hline & & $44 \%$ & $64 \%$ & $86 \%$ & $96 \%$ \\
\hline \multirow{4}{*}{$\begin{array}{l}\text { 1. Year-1 HIV incidence } \\
\text { (no risk compensation) }\end{array}$} & $\begin{array}{l}9.0 \text { per } 100 \\
\text { person-years }\end{array}$ & $\begin{array}{l}\text {-GBP 23,010 } \\
(- \text { EUR 31,305) }\end{array}$ & $\begin{array}{l}- \text { GBP } 36,764 \\
(- \text { EUR } 50,017)\end{array}$ & $\begin{array}{l}\text {-GBP 44,504 } \\
\text { (-EUR 60,548) }\end{array}$ & $\begin{array}{l}\text {-GBP 46,850 } \\
(- \text { EUR 63,739) }\end{array}$ \\
\hline & $\begin{array}{l}5.2 \text { per } 100 \\
\text { person-years }\end{array}$ & $\begin{array}{c}\text { GBP } 7,786 \\
(\text { EUR 10,593) }\end{array}$ & $\begin{array}{l}\text {-GBP } 15,572 \\
(- \text { EUR } 21,186)\end{array}$ & $\begin{array}{l}\text {-GBP 28,717 } \\
(- \text { EUR 39,069) }\end{array}$ & $\begin{array}{c}\text {-GBP } 32,701 \\
(-E U R \text { 44,490) }\end{array}$ \\
\hline & $\begin{array}{l}\text { 3.3 per } 100 \\
\text { person-years }\end{array}$ & $\begin{array}{l}\text { GBP } 49,762 \\
\text { (EUR 67,701) }\end{array}$ & $\begin{array}{l}\text { GBP 13,296 } \\
\text { (EUR 18,089) }\end{array}$ & $\begin{array}{l}\text {-GBP 7,227 } \\
\text { (EUR 9,832) }\end{array}$ & $\begin{array}{l}\text {-GBP } 13,446 \\
\text { (EUR 18,293) }\end{array}$ \\
\hline & $\begin{array}{l}2.0 \text { per } 100 \\
\text { person-years }\end{array}$ & $\begin{array}{c}\text { GBP } 124,421 \\
(\text { EUR } 169,275)\end{array}$ & $\begin{array}{l}\text { GBP } 64,630 \\
\text { (EUR 87,929) }\end{array}$ & $\begin{array}{l}\text { GBP } 30,980 \\
\text { (EUR 42,148) }\end{array}$ & $\begin{array}{c}\text { GBP 20,783 } \\
\text { (EUR 28,275) }\end{array}$ \\
\hline \multirow{4}{*}{$\begin{array}{l}\text { 2. Risk compensation } \\
\text { in those given PrEP, } \\
\text { as percentage increase } \\
\text { in HIV incidence } \\
\text { (Year-1 HIV incidence: } \\
\mathbf{3 . 3} \text { per } \mathbf{1 0 0} \text { person-years) }\end{array}$} & $0 \%$ & $\begin{array}{l}\text { GBP } 49,762 \\
\text { (EUR 67,701) }\end{array}$ & $\begin{array}{c}\text { GBP 13,296 } \\
\text { (EUR 18,089) }\end{array}$ & $\begin{array}{l}\text {-GBP } 7,227 \\
\text { (-EUR 9,832) }\end{array}$ & $\begin{array}{l}\text {-GBP } 13,446 \\
\text { (-EUR 18,293) }\end{array}$ \\
\hline & $10 \%$ & $\begin{array}{l}\text { GBP } 66,780 \\
\text { (EUR 90,854) }\end{array}$ & $\begin{array}{c}\text { GBP 18,078 } \\
\text { (EUR 24,595) }\end{array}$ & $\begin{array}{l}\text {-GBP 6,239 } \\
\text { (-EUR 8,488) }\end{array}$ & $\begin{array}{c}\text {-GBP } 13,222 \\
(-E U R ~ 17,989)\end{array}$ \\
\hline & $20 \%$ & $\begin{array}{c}\text { GBP } 89,608 \\
\text { (EUR 121,912) }\end{array}$ & $\begin{array}{l}\text { GBP 23,465 } \\
\text { (EUR 31,924) }\end{array}$ & $\begin{array}{c}\text {-GBP } 5,218 \\
\text { (-EUR 7,099) }\end{array}$ & $\begin{array}{l}\text {-GBP } 12,997 \\
(- \text { EUR } 17,682)\end{array}$ \\
\hline & $30 \%$ & $\begin{array}{c}\text { GBP } 121,837 \\
\text { (EUR 165,759) }\end{array}$ & $\begin{array}{c}\text { GBP } 29,582 \\
\text { (EUR 40,246) }\end{array}$ & $\begin{array}{l}\text {-GBP } 4,161 \\
(- \text { EUR } 5,661)\end{array}$ & $\begin{array}{l}\text {-GBP } 12,769 \\
(- \text { EUR } 17,372)\end{array}$ \\
\hline \multirow{4}{*}{$\begin{array}{l}\text { 3. Percentage reduction in } \\
\text { ARV treatment cost from } \\
2019 \\
\text { (Year-1 HIV incidence: } \\
\text { 3.3 per } 100 \text { person-years; } \\
\text { risk compensation in } \\
\text { those given PrEP of } \\
20 \% \text { HIV incidence } \\
\text { increase) }\end{array}$} & $\begin{array}{c}\text { o\% GBP } 4,741 \\
(\text { EUR } 6,450)\end{array}$ & $\begin{array}{l}\text { GBP } 89,608 \\
\text { (EUR 121,912) }\end{array}$ & $\begin{array}{l}\text { GBP } 23,465 \\
(\text { EUR } 31,924)\end{array}$ & $\begin{array}{c}\text {-GBP 5,218 } \\
(- \text { EUR 7,099) }\end{array}$ & $\begin{array}{l}\text {-GBP 12,997 } \\
\text { (-EUR 17,682) }\end{array}$ \\
\hline & $\begin{array}{c}\mathbf{3 0} \% \text { GBP } \mathbf{3 , 0 3 2} \\
(\text { EUR 4,125) }\end{array}$ & $\begin{array}{c}\text { GBP 98,864 } \\
\text { (EUR 134,504) }\end{array}$ & $\begin{array}{c}\text { GBP } 32,721 \\
\text { (EUR 44,517) }\end{array}$ & $\begin{array}{c}\text { GBP 4,038 } \\
\text { (EUR 5,494) }\end{array}$ & $\begin{array}{l}\text {-GBP } 3,741 \\
(- \text { EUR 5,090) }\end{array}$ \\
\hline & $\begin{array}{c}50 \% \text { GBP } 2,371 \\
(\text { EUR 3,226) }\end{array}$ & $\begin{array}{c}\text { GBP } 105,034 \\
\text { (EUR 142,899) }\end{array}$ & $\begin{array}{l}\text { GBP } 38,891 \\
\text { (EUR 52,911) }\end{array}$ & $\begin{array}{c}\text { GBP } 10,208 \\
\text { (EUR 13,888) }\end{array}$ & $\begin{array}{l}\text { GBP 2,429 } \\
\text { (EUR 3,305) }\end{array}$ \\
\hline & $\begin{array}{c}80 \% \text { GBP } 948 \\
\text { (EUR } 1,290)\end{array}$ & $\begin{array}{l}\text { GBP } 114,289 \\
(\text { EUR } 155,490)\end{array}$ & $\begin{array}{l}\text { GBP } 48,146 \\
\text { (EUR } 65,503)\end{array}$ & $\begin{array}{l}\text { GBP } 19,463 \\
\text { (EUR 26,479) }\end{array}$ & $\begin{array}{l}\text { GBP 11,684 } \\
\text { (EUR 15,896) }\end{array}$ \\
\hline \multirow{4}{*}{$\begin{array}{l}\text { 4. Percentage reduction } \\
\text { in PrEP BNF annual } \\
\text { drug price } \\
\text { (Year-1 HIV incidence: } \\
\text { 3.3 per } 100 \text { person-years; } \\
\text { risk compensation in those } \\
\text { given PrEP - } 20 \% \text { HIV } \\
\text { incidence increase; } \\
\text { 30\% reduction in } \\
\text { ARV treatment cost } \\
\text { after 2019) }\end{array}$} & $\begin{array}{c}\text { o\% GBP } 4,331 \\
\text { (EUR 5,892) }\end{array}$ & $\begin{array}{c}\text { GBP 98,864 } \\
\text { (EUR 134,504) }\end{array}$ & $\begin{array}{c}\text { GBP } 32,721 \\
\text { (EUR 44,517) }\end{array}$ & $\begin{array}{c}\text { GBP 4,038 } \\
\text { (EUR 5,494) }\end{array}$ & $\begin{array}{c}\text {-GBP } 3,741 \\
(- \text { EUR } 5,090)\end{array}$ \\
\hline & $\begin{array}{c}21 \% \text { GBP } 3,403^{\mathrm{f}} \\
(\text { EUR } 4,630)\end{array}$ & $\begin{array}{l}\text { GBP 66,260 } \\
\text { (EUR 90,147) }\end{array}$ & $\begin{array}{l}\text { GBP } 13,893 \\
\text { (EUR 18,901) }\end{array}$ & $\begin{array}{c}\text {-GBP } 8,816 \\
\text { (-EUR 11,994) }\end{array}$ & $\begin{array}{l}\text {-GBP } 14,974 \\
(- \text { EUR } 20,372)\end{array}$ \\
\hline & $\begin{array}{c}43 \% \text { GBP } 2,475^{\circ} \\
(\text { EUR } 3,367)\end{array}$ & $\begin{array}{c}\text { GBP } 33,656 \\
\text { (EUR 45,789) }\end{array}$ & $\begin{array}{l}\text {-GBP 4,934 } \\
\text { (-EUR 6,713) }\end{array}$ & $\begin{array}{l}\text {-GBP 21,669 } \\
\text { (-EUR 29,481) }\end{array}$ & $\begin{array}{l}\text {-GBP } 26,208 \\
(-E U R ~ 35,656)\end{array}$ \\
\hline & $\begin{array}{l}90 \% \text { GBP } 431^{h} \\
\text { (EUR 586) }\end{array}$ & $\begin{array}{l}\text {-GBP } 38,072 \\
(-E U R ~ 51,797)\end{array}$ & $\begin{array}{c}\text {-GBP } 46,355 \\
\text { (-EUR 63,066) }\end{array}$ & $\begin{array}{l}\text {-GBP } 49,947 \\
\text { (-EUR 67,953) }\end{array}$ & $\begin{array}{c}\text {-GBP 50,921 } \\
\text { (-EUR 69,278) }\end{array}$ \\
\hline
\end{tabular}

\section{Colour coding}

$$
\text { Cost saving }
$$

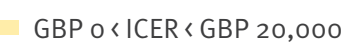

GBP $20,000<$ ICER $<$ GBP 30,000 (EUR 27,210 <ICER < EUR 40,815)
- ICER > GBP 30,000 (ICER > EUR 40,815)

BNF: British National Formulary; GUM: genitourinary medicine; GUMCAD: GUM clinic activity dataset; MSM: men who have sex with men; STI: sexually transmitted infection; UK: United Kingdom.

${ }^{a}$ First parameter combination (i.e. Year-1 HIV incidence of 3.3 per 100 person-years) assumed within second combination, first and second within third, etc.

${ }^{\mathrm{b}} 44 \%$ was the efficacy level reported in the iPrEx trial; $86 \%$ was the UK PROUD trial observed clinical effectiveness level, while $64 \%$ and $96 \%$ were the lower- and upper-bound $90 \%$ confidence intervals reported in this latter trial $[2,3]$.

c Reported HIV incidence in the deferred part (no PrEP, $n=267$ MSM) of the PROUD trial [2].

${ }^{d}$ Estimated HIV incidence in HIV-negative MSM with documented rectal bacterial STI diagnosis in 2012, GUMCAD analysis.

${ }^{e}$ Estimated HIV incidence in all HIV-negative MSM GUM attendees in 2012, GUMCAD analysis.

$\mathrm{f}_{21} \%$ reduction in PrEP drug price due to $50 \%$ event-based dosing i.e. prorated 5.5 tablets per 7 -day. This assumed that if an MSM was prescribed event-based dosing then only four tablets would be dispensed for every 7-day i.e. 4/7 of the drug cost. Event-based dosing frequency based on the findings reported in the IPERGAY trial [4]. Service provision through GUM clinics remained the same, as frequency of monitoring remained the same.

${ }^{8} 43 \%$ reduction in PrEP drug price due to $100 \%$ event-based dosing (four tablets per 7 -day).

${ }^{\mathrm{h}} 90 \%$ reduction in PrEP drug price due to fall in current tenofovir disoproxil/emtricitabine price following patent expiry of the PrEP drug used. This is an arbitrary assumption. The future price is dependent on market competition. The exact timing of when this will happen, however, is uncertain. The patents for tenofovir disoproxil and emtricitabine expired in 2016 and July 2017 , respectively. However, Truvada as a combination tablet containing both tenofovir disoproxil/emtricitabine has a supplementary protection certificate (SPC) providing market exclusivity protection until February 2020, although this SPC is being challenged [39]. 


\section{FIGURE 4}

Univariate sensitivity of pre-exposure prophylaxis (PrEP) incremental cost-effectiveness ratio (ICER) around base case for $^{2}$ plausible ranges ${ }^{\mathrm{b}}$ of key parameters, 2014/15 cost values

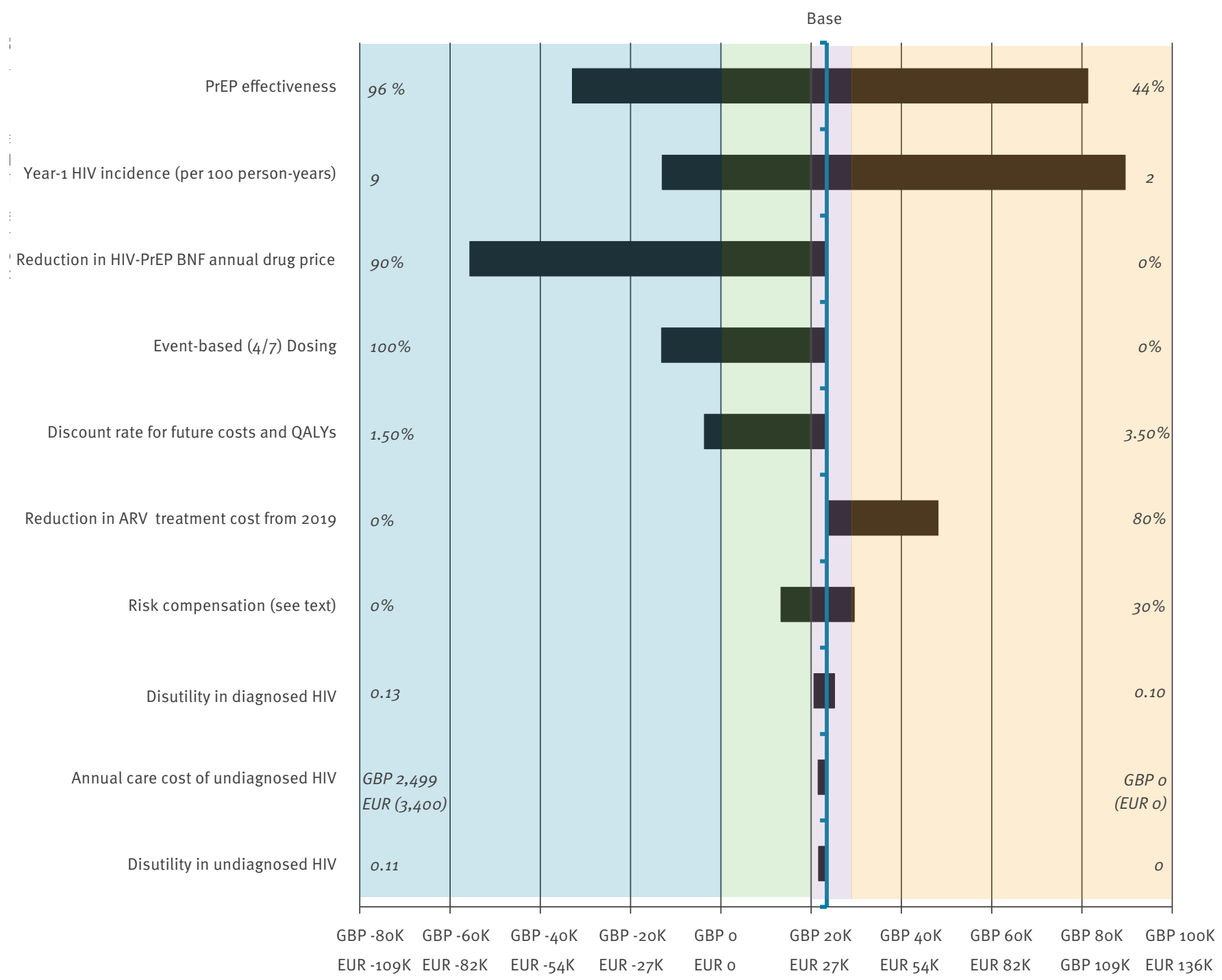

ARV: antiretroviral; BNF: British National Formulary; QALY: quality-adjusted life year.

a Base case ICER + GBP 23,500 (EUR 31,900) per QALY gained, set at 64\% PrEP effectiveness and a $20 \%$ increase in HIV incidence in those given PrEP due to risk compensation (see text).

${ }^{\mathrm{b}}$ Extremes of parameter ranges shown at either end of horizontal bars.

Individuals given PrEP will be managed via GUM clinics; for a one year programme, each individual will have five visits to the clinic, at month $0,1,3,6$, and 9 . The first visit includes assessment of clinical need for PrEP, confirmation of HIV and STI status, and measurement of renal function. Subsequent visits are for monitoring of drug adherence, tolerability, and safety, together with quarterly checking of HIV and STI status [2]. The additional elements of GUM clinic care directly attributable to PrEP were micro-costed (see supplementary material [12]).

\section{Estimating HIV incidence}

GUMCAD data on HIV-negative clinic attending MSM for 2009 to 2013 were extracted. Diagnosis or not of any bacterial STI in the previous year was used to indicate recent condomless anal intercourse and to stratify the future risk of being diagnosed with HIV. Those with a bacterial STI in the previous year were labelled 'highrisk' and eligible for PrEP, and those without as having 'medium-risk' for HIV acquisition [14]. To estimate current HIV incidence in these strata, records were used of MSM with at least one additional documented HIV test between 43 to 365 days after the first HIV test 
TABLE 1

Economic parameter estimates used in the two principal scenarios (providing PrEP or not), and value or range explored in sensitivity analyses, England, 2014/15 cost values

\begin{tabular}{|c|c|c|c|}
\hline Parameter & Value & $\begin{array}{l}\text { Sensitivity analyses range } \\
\text { (min. to max. value of } \\
\text { scenarios considered) }\end{array}$ & Explanatory notes and data source \\
\hline Discount rate (cost) & $3.5 \%$ & $1.5 \%-3.5 \%$ & [7] \\
\hline Discount rate (QALYs) & $3.5 \%$ & $1.5 \%-3.5 \%$ & [7] \\
\hline \multicolumn{4}{|l|}{ Costs } \\
\hline Annual cost of PrEP drug & $\begin{array}{l}\text { GBP } 4,331 \\
(\text { EUR } 5,892)\end{array}$ & $\begin{array}{c}\text { GBP } 433 \text { - GBP } 4,331 \\
\text { (EUR } 589 \text { - EUR 5,892) } \\
\text { Discount range: } \\
20 \% \text { to } 90 \% \\
\end{array}$ & $\begin{array}{l}\text { [32] (last accessed } 5 \text { August 2016); price } \\
\text { excludes VAT and was directly applied to the } \\
\text { cost-effectiveness analysis }\end{array}$ \\
\hline Annual cost of PrEP-related GUM tariffs & $\begin{array}{l}\text { GBP } 176 \\
(\text { EUR 239) }\end{array}$ & ND & {$[2,33]$, see also supplementary material [12] } \\
\hline PEPSE drug cost ${ }^{\text {a }}$ (averted in those taking PrEP) & $\begin{array}{c}\text { GBP } 772^{\mathrm{a}} \\
\text { (EUR 1,050) } \\
\text { per PEPSE } \\
\text { course }\end{array}$ & NA & $\begin{array}{l}\text { [32] (BNF last accessed } 5 \text { August 2016); price } \\
\text { excludes VAT and was directly applied to the } \\
\text { cost-effectiveness analysis }\end{array}$ \\
\hline $\begin{array}{l}\text { PEPSE GUM clinic costs (averted in those taking } \\
\text { PrEP) }\end{array}$ & $\begin{array}{l}\text { GBP } 250 \\
\text { (EUR 340) } \\
\text { per PEPSE } \\
\text { course }\end{array}$ & NA & [33] (adapted to the current study) \\
\hline Annual cost of an undiagnosed HIV infection & $\begin{array}{l}\text { GBP o } \\
(\text { EUR o) }\end{array}$ & $\begin{array}{l}\text { GBP o - GBP 2,499 } \\
\text { (EUR o - EUR 3,400) }\end{array}$ & $\begin{array}{l}\text { Assumption; GBP } 2,499 \text { based on HIV care } \\
\text { costs for individuals diagnosed at CD } 4+>200 \\
\text { cells per mm3 not on ARV treatmentb }[17,21]\end{array}$ \\
\hline $\begin{array}{l}\text { Annual cost of ARV treatment per } \\
\text { HIV-positive individual }\end{array}$ & $\begin{array}{l}\text { GBP 4,741 } \\
\text { (EUR 6,450) }\end{array}$ & $\begin{array}{l}\text { Price reductions from } \\
\text { 2019: } \\
\text { range } 0 \% \text { to } 80 \%\end{array}$ & [20]c \\
\hline $\begin{array}{l}\text { Annual care cost of } \mathrm{HIV}+\mathrm{CD} 4>200 \text { cells per } \\
\mathrm{mm}^{3}\end{array}$ & $\begin{array}{l}\text { GBP } 4,734 \\
\text { (EUR 6,441) }\end{array}$ & ND & {$[17,21]$} \\
\hline Annual care cost of $\mathrm{HIV}+\mathrm{CD}_{4}<200$ cells per $\mathrm{mm}^{3}$ & $\begin{array}{l}\text { GBP 7,479 } \\
(\text { EUR 10,175) }\end{array}$ & ND & {$[17,21]$} \\
\hline Time to $\mathrm{CD}_{4}+$ recovery from $<200$ cells per $\mathrm{mm}^{3}$ & 3 months & NA & Based on analysis of HIV data [18] \\
\hline \multicolumn{4}{|l|}{ QALY values } \\
\hline Disutility between HIV infection and diagnosis & 0 & $0-0.11$ & Assumption [34] \\
\hline $\begin{array}{l}\text { Disutility associated with HIV infection - per } \\
\text { annum }\end{array}$ & 0.11 & $0.10-0.13$ & [34] \\
\hline Utility values in UK men aged over 75 years $^{d}$ & 0.75 & NA & [35] \\
\hline
\end{tabular}

ARV: antiretroviral; BNF: British National Formulary; GUM: genitourinary medicine; max: maximum; min: minimum; NA: not applicable; ND: not done; NHS: National Health Service; NICE: The National Institute for Health and Care Excellence; PEPSE: post-exposure prophylaxis; PrEP: pre-exposure prophylaxis; QALY: quality-adjusted life year; VAT: value added tax; UK: United Kingdom.

a This price represents the highest possible cost of current PEPSE drug recommended for use by NHS England (tenofovir disoproxil/ emtricitabine/raltegravir) based on BNF list price, excluding VAT for the cost-effectiveness analysis in accordance with NICE Methods Guide.

${ }^{b}$ Cost excludes specific HIV-related costs such as $\mathrm{CD}_{4}+$ and viral load measurements, and resistance testing (personal communication, $\mathrm{V}$ Cambiano, December 2015).

c Principal scenario used NHS England reported spend on ARV treatment. In sensitivity analyses, although actual timing of availability of generic ARVs for treatment is unknown, sensitivity analyses explored potential availability from 2019. This was based on the estimated patent expiration of individual compounds of the combination ARV treatment tenofovir disoproxil/emtricitabine/efavirenz (proprietary name: Atripla) by 2018 [36]. Combination tenofovir disoproxil/emtricitabine/efavirenz is one of the British HIV Association preferred choice of ARV treatment to begin with in therapy-naïve patients [37].

${ }^{d}$ We assumed that an HIV-positive individual has a life-expectancy of 75 years [38]. Given that the life-expectancy at birth for males in England (2010 to 2012 Office for National Statistics estimates) was 79 years, this meant that an HIV-positive individual who dies at age 75 years would have lost four years of quality of life [16]. We combined this last four years with the utility values among UK men aged above 75 years ( 0.75 per year), which was obtained from the EQ-5D utility values for UK male population, to obtain the QALY losses during these final four years of life lost consequent to earlier deaths related to HIV [35]. 
Population size and HIV incidence in men having sex with men (MSM), England, 2012

\begin{tabular}{|c|c|c|c|}
\hline HIV-negative MSM by risk stratum & MSM numbers ${ }^{\mathrm{a}}$ & $\begin{array}{l}\text { Annual HIV incidence, per } 100 \\
\text { person-years }(95 \% \mathrm{Cl})\end{array}$ & $\begin{array}{l}\text { Annual HIV } \\
\text { infections }^{\text {a }}\end{array}$ \\
\hline \multicolumn{4}{|l|}{ a. HIV incidence in GUM clinic attendees (directly estimated ${ }^{b}$ ) } \\
\hline $\begin{array}{l}\text { High-risk - GUM clinic attendees with bacterial STI in previous year and/ } \\
\text { or at first attendance of year }\end{array}$ & 17,400 & $3.3(2.8-4.9)^{c}$ & $570^{d}$ \\
\hline $\begin{array}{l}\text { Medium-risk - GUM clinic attendees with no recorded bacterial STI in } \\
\text { previous year or at first attendance of year }\end{array}$ & 68,100 & $1.5(1.3-1.8)^{c}$ & $1,020^{d}$ \\
\hline \multicolumn{4}{|l|}{ b. Overall HIV incidence, England } \\
\hline PHE back-calculatione & & & 2,790 \\
\hline \multicolumn{4}{|l|}{ c. HIV incidence in non-GUM clinic attendees (indirectly estimated } \\
\hline Low-risk - HIV-negative non-GUM clinic attendees & 395,000 & 0.3 & 1,200 \\
\hline
\end{tabular}

$\mathrm{Cl}$ : confidence interval; GUM: genitourinary medicine; ONS: Office for National Statistics; MPES: multi-parameter evidence synthesis; Natsal: National Survey on Sexual Attitudes and Lifestyles; PHE: Public Health England; STI: sexually transmitted infection.

a Numbers rounded to three significant figures or nearest 10.

${ }^{b}$ Estimated using 2013 Genitourinary Medicine Clinical Activity Dataset - GUMCAD [11].

c As observed in re-attending sub-group.

${ }^{d}$ Applying observed incidence to whole group and rounded to three significant figures or nearest 10.

e Year 2012 estimated numbers, using methodology as described in Birrell et al., 2013 [30].

${ }^{f}$ Estimated 1,200 annual infections calculated by deducting number of infections among GUM clinic attendees (high-risk and medium-risk; $1,595)$ from overall annual HIV incidence $(2,790)$ [30]. Low-risk population size of 395,000 (i.e. non-GUM attending MSM) estimated using a combination of MPES (England and Wales, aged 15-44 years), ONS (England and Wales population estimates for mid-2012), and Natsal-3 (proportion of MSM by age group), to obtain an estimate of the non-GUM attending MSM population in England for ages $15-74$ years $[1,15,16]$. HIV incidence in this low-risk group $(1,200$ annual infections per 395,000 population) rounded to 0.3 per 100 person-years.

documented in 2012, the most recent year with sufficient data (followed-up to end 2013) for analysis [14]. HIV incidence estimation methodology follows that used in Desai et al. [14].

MSM who did not attend a GUM clinic were assumed to be at 'low-risk' [14] (see also supplementary material [12]). To estimate HIV incidence in this stratum, total MSM numbers were calculated by combining the male proportion reporting same-sex partnerships in a 201012 national survey with 2012 male population estimates $[15,16]$. Estimated MSM living with HIV (diagnosed and undiagnosed) and GUM attending HIV-negative MSM were subtracted to get the denominator of those at low-risk [1]. Estimated HIV infections that occur in highand medium-risk MSM were subtracted from the backcalculation estimate of all 2012 HIV infections in MSM to give the numerator for those at low-risk.

MSM eligible for PrEP begin at high-risk and move to medium- or low-risk at a changing probability. Lifetime HIV incidence combined movement between risk strata with estimated stratum-specific HIV incidence. Follow-up of high-risk MSM clinic attendees informed the proportions that stayed high-risk with bacterial STI diagnoses each year, those that became medium-risk who attended a clinic annually without bacterial STI diagnosis, and those without clinic attendance who became low-risk. Allowance was made for any transition from low- or medium-risk back to medium- or highrisk. If in 2013, $\mathrm{x} \%$ of MSM who began as high-risk in 2009 remained high-risk, $y \%$ had become mediumrisk, and $z \%$ low-risk, and HIV incidence was $H, M$, and $\Lambda$ for high, medium, and low-risk respectively, then the weighted average HIV incidence in 2013 was $\left(x \%{ }^{\star} H\right)+\left(y \%{ }^{\star} M\right)+(z \% \star \Lambda)$. Similarly calculated weighted HIV incidence averages were used for years 2010, 2011 and 2012. By assuming the same rate of change in risk from 2009 through 2013 and the same HIV incidence by risk stratum, future HIV incidence in 2017 through 2020 was estimated for MSM who began as high-risk in 2016 (PrEP programme year-1). After year-5 in 2020, future annual HIV incidence was interpolated using a constant rate of reduction until it reached $\Lambda$, and subsequently kept at $\Lambda$ until age 75 years, after which risk of HIV acquisition was assumed to be zero. This approach created a declining HIV incidence over time. A slightly higher number remained susceptible in the PrEP group due to their PrEP protection during the first year. Therefore, over the subsequent lifetime to age 75 years, the absolute number of HIV infections each year was slightly greater in the PrEP group compared with the non-PrEP group (Figure 2).

\section{Economic evaluation}

A national guide for technology appraisals was followed [7]. PrEP users were assumed not to require HIV post-exposure prophylaxis following sexual exposure (PEPSE). Lifetime HIV infection care cost (excluding ARV costs) were stratified by $\mathrm{CD}_{4}+$ status at diagnosis $[7,17]$. HIV surveillance data were used to estimate average time to diagnosis once infected, CD4+ count at diagnosis, and rate of $\mathrm{CD}_{4}+$ recovery upon ARV commencement [18] (see also supplementary material [12]). Prompt initiation of ARV treatment following diagnosis was assumed [19]. 
Drug treatment costs used average 2013-15 NHS England ARV cost [20]. Future costs and QALYs were discounted annually by $3.5 \%$ and adjusted to $2014 / 15$ GBP values (EUR values presented in parentheses, using year end 31 December 2015 historical exchange rates of GBP 1 equals EUR 1.3605) [7,21]. Economic parameters are presented in Table 1.

Model outputs included number of new HIV infections and the ICER, as cost per QALY gained, of PrEP compared with no PrEP. Budget impact analyses were presented in present 2014/15 values and included value added tax (VAT: $+20 \%$ ) on PrEP drug costs [7]. PrEP service investment time to break-even was calculated as the years to when the cumulative savings from HIV infections averted in year-1 began to exceed PrEP costs in year-1.

\section{Risk compensation}

Published evidence suggests increased frequency of condomless anal sex subsequent to PrEP use and increased STI diagnoses [2,22]. Risk compensation would also lead to an increase in HIV exposure. With PrEP scale-up, adherence may reduce and thereby increase HIV transmission. To explore risk compensation, an arbitrary increase of HIV incidence by $20 \%$ in those given PrEP was assumed in the principal scenarios. At $64 \%$ PrEP effectiveness, for example, annual HIV incidence is $(100 \%-64 \%) * H=36 \% * H$, where, $H=H I V$ incidence in high-risk MSM. If $H$ is increased by $20 \%$ due to risk compensation, then annual HIV incidence becomes $(100-64 \%){ }^{*}(100 \%+20 \%){ }^{*} H=43.2 \%$ * $H$.

\section{Sensitivity analyses}

Sensitivity analyses explored plausible ranges of key parameter values (Table 1). Univariate sensitivity analyses were based on cautious choices considered more plausible with substantial scale-up. The scenario with $64 \%$ PrEP effectiveness and risk compensation was the preferred benchmark and corresponding ICERs were plotted on a tornado diagram.

Multivariate sensitivity analyses were conducted to illustrate the margin of certainty around whether or not PrEP would remain cost-effective, at different PrEP effectiveness level (Figure 3). Due to the nature of the uncertainties, full probabilistic sensitivity analysis was not possible.

\section{Results}

An estimated 466,000 HIV-negative MSM aged between 15 to 75 years-old live in England in 2012, 85,500 (23\%) of whom attended GUM clinics during that year. A fifth of the 85,500 (17,400 MSM) had a documented bacterial STI diagnosis i.e. proxy for high risk. Over time, GUMCAD data have shown an increase in the number of HIV-negative MSM GUM attendees, as well as the subset diagnosed with bacterial STI. Thus, the 5,000 person-years PrEP covered $29 \%$ of the GUMCAD identified high-risk cohort (who may not represent all highrisk MSM as not all attended GUM clinics [23]), 6\% of all
HIV-negative MSM GUM attendees, and just $1 \%$ of the estimated HIV-negative MSM population in England.

The HIV incidence observed in the high-risk PrEPeligible stratum was 3.3 per 100 person-years (95\% Cl: 2.8-4.9 per 100 person-years), and 1.5 per 100 person-years ( $95 \% \mathrm{Cl}: 1.3-1.8$ per 100 person-years) in the medium-risk stratum. In the low-risk MSM stratum the indirectly estimated HIV incidence was 0.3 per 100 person-years (Table 2). The HIV incidence estimates showed that GUM attending MSM had higher HIV risk than non-GUM attending MSM.

Of the 11,742 MSM without diagnosed HIV and with a recent bacterial STI (proxy for high HIV risk), who attended clinic in 2009 (the first of a five year, 20092013 , longitudinal analysis), only $26 \%$ were categorised as high-risk in 2010. This decrease in the proportion of the initial 2009 attendees categorised as high-risk in subsequent years continued through 2011, 2012 and 2013 , to $10 \%, 7 \%$ and $5 \%$ (see supplementary material [12]). Consequently, there was a large reduction in the weighted average annual HIV incidence for year-2 to year-5 (Figure 2). Interpolating the declining risk behaviour in the cohort and subsequent HIV acquisition forward, the annual HIV incidence reached the lower risk tier of 0.3 per 100 person-years annually by year-9, after which it was kept constant until age 75 years.

Combining the weighted average annual HIV incidence for MSM and the age distribution of MSM clinic attendees in 2013 and 2014, the estimated lifetime HIV incidence to age 75 years in an MSM clinic attendee who began year-1 at high-risk, was $16.96 \%$.

Applying a $20 \%$ HIV incidence increase to those given PrEP in year-1, as a risk compensation adjustment, the estimated cumulative HIV incidence to age 75 years was reduced from $16.96 \%$ (no PrEP) to $15.4 \%$ at $64 \%$ PrEP effectiveness, while at $86 \%$ effectiveness, it fell to $14.6 \%$.

After the year-1 high-risk period, HIV incidence reduced to 1.35 per 100 person-years and PrEP was no longer indicated. Moreover, a small fraction of those who were protected by PrEP during the first year became infected later in life. The contribution of PrEP, given only during the year-1 high-risk period, to reducing lifetime HIV risk was modest, impacting on close to $20 \%$ of lifetime risk, because of the relatively short period that MSM remained at high risk (see supplementary material [12]).

\section{Economic evaluation}

Without PrEP in year-1, an estimated 848 HIV infections occurred, producing future discounted HIV care costs of GBP 84.3 million (EUR 115 million), and a loss of 1,830 QALYS (discounted). Almost half of these infections occurred within the first 10 years (see supplementary material [12]). 
Assuming daily PrEP at $86 \%$ effectiveness (with risk compensation), an estimated 730 lifetime HIV infections occurred. Year-1 PrEP cost (drug and GUM clinic) of GBP 22.5 million (EUR 30.7 million) prevented GBP 24.1 million (EUR 32.9 million) HIV care costs (discounted) and GBP 256,000 (EUR 348,000) PEPSE-related costs, saved 361 QALYs (discounted), and over a lifetime was cost-saving (i.e. ICER is negative), compared with no PrEP. Delivering PrEP to 5,000 high-risk MSM resulted in 137 less year-1 HIV infections. However, 19 of these 137 acquired HIV while at medium- or low-risk later in life, reducing the total infections prevented to 118 . Nevertheless, these 19 infections were delayed with corresponding reductions in costs and QALY losses.

At $64 \%$ PrEP effectiveness (with risk compensation), the lifetime HIV infections were 767 . Year-1 PrEP service cost of GBP 22.5 million (EUR 30.7 million) prevented GBP 16.5 million (EUR 22.4 million) HIV care costs (discounted) and GBP 256,000 (EUR 348,000) PEPSErelated costs, and saved 247 QALYs (discounted). Under this scenario, the ICER increased to + GBP 23,500 (EUR 31,900), just above the current cost-effectiveness threshold for England [7]. The reduced effectiveness gave 94 less year-1 HIV infections, although 13 of the 94 acquired HIV in later years.

The ICER was very sensitive to assumptions about HIV incidence in the PrEP eligible group, PrEP effectiveness when scaled-up, PrEP drug costs, and future reductions in the cost of ARV treatment (Figure 4).

PrEP was much less cost-effective if HIV incidence was 2 per 100 person-years (the estimated overall HIV incidence in MSM GUM clinic attendees), or if PrEP effectiveness dropped to $44 \%$. Similarly, albeit to a lesser extent, reduced future treatment costs produced a less favourable ICER for PrEP. However, a more favourable ICER resulted through reducing PrEP drug costs, either through price reduction or reduced dosing frequency from daily to event-based.

If, under scale-up, PrEP stayed $86 \%$ effective with $20 \%$ HIV risk increase (risk compensation adjustment), then for most parameter combinations a PrEP policy stays cost-effective, unless the eligible group HIV incidence was 2 per 100 person-years or less (Figure 3). If, however, effectiveness was $64 \%$ with the same degree of risk compensation, then a PrEP service will only be cost-effective if year-1 incidence is over 3.3 per 100 person-years and there is no change in future HIV treatment costs (i.e. ignoring availability for treatment of generic ARVs by 2019, see notes for Table 1), or if PrEP drug cost is reduced.

\section{Budgetary implications}

In a single year, a PrEP service of 5,000 person years cost GBP 26.9 million (EUR 36.6 million), at current British National Formulary (BNF) list price (inclusive of $20 \%$ VAT). As HIV care costs accrued over time, it took many years before investment in the first year was recovered. At $86 \%$ PrEP effectiveness, it took 23 years of cumulative savings from HIV care cost averted for the year-1 investment to break even and 33 years if PrEP was only $64 \%$ effective, both assuming risk compensation.

If there was a substantial reduction in PrEP drug price (e.g. by $90 \%$ ), the budget to cover 5,000 person years became GBP 3.48 million (EUR 4.73 million). Breakeven of year-1 investment happened by the fifth year at $86 \%$ effectiveness or by the sixth year at $64 \%$ effectiveness, again assuming risk compensation.

Time to break-even of the initial year of PrEP was extended should future HIV treatment costs reduce. At current BNF list price, a $30 \%$ reduction in future ARV treatment costs from 2019 onwards increased the time to break-even of the one-year investment in PrEP in 2016 to 38 years, assuming $64 \%$ PrEP effectiveness with risk compensation.

\section{Discussion}

Oral PrEP given to MSM at high HIV risk, assuming good adherence and correspondingly high clinical effectiveness, was potentially cost-effective in England. The ICERs, however, were very sensitive to key parameters such as the risk of HIV for PrEP recipients and adherence (effectiveness). When PrEP is scaled-up to service provision level there is doubt that the values for these parameters observed in clinical trial settings will apply. Moreover, at the current BNF price the budgetary impact of a modest annual programme of 5,000 PrEP person years was considerable.

The cost-effectiveness of PrEP scale-up depends first on reaching those at high risk of HIV, who need to be identified, offered and to accept PrEP; if many at medium-risk take PrEP, HIV incidence in those taking PrEP will be overestimated. Second, PrEP adherence may be lower with scale-up than in smaller clinical trials; results from 'real-world' effectiveness trials, which generally recruit committed early adopters who may be at exceptionally high-risk, may not be repeated in programmes for all at high-risk [24]. Third, there is uncertainty about whether or not condomless anal intercourse frequency will increase in those given PrEP (risk compensation), leading to more exposures and increased HIV in those with poor PrEP adherence as well as increased bacterial STIS and hepatitis C, thus blunting PrEP benefit; so far a possible HIV incidence increase mediated through diminished adherence during scale-up has not been observed, but there is emerging evidence suggesting risk compensation and bacterial STI increase in those on PrEP [25]. Sensitivity analyses of plausible combinations of these factors did not give a high degree of certainty that the ICER for PrEP would be below GBP 20,000 (EUR 27,210) per QALY gained [7]. Moreover, despite differences in model structure and input assumptions that were appropriate for England, these findings were broadly in agreement with economic evaluations from other 
high income countries [26-29], which found ICERs to be highly dependent on HIV incidence, costs of the PrEP drug and adherence-related effectiveness. This analysis highlights critical considerations for PrEP implementation in other European countries, even if their HIV epidemic is different, as the problems arising around implementation, financial considerations, and programme sustainability are common.

A key strength of this study was the use of empirical data on many thousands of MSM attending GUM clinics in England over a contemporary period to measure HIV incidence and risk turnover. A critical assumption was that future HIV incidence in MSM GUM clinic attendees will replicate that observed between 2009 and 2013, and further consequences of any recent changes in sexual behaviour were not captured. However, it was reasonable to extrapolate forward current HIV incidence estimates given the scale and timeliness of the source GUMCAD data and the recent back-calculation estimates that showed no change in overall HIV incidence in MSM $[1,30]$.

A major limitation of our analysis was the use of a static decision analysis approach instead of a dynamic transmission model, as it did not quantify the benefit of PrEP on the wider HIV epidemic in England, including the benefits for those not given PrEP. Therefore, there was an underestimation of the total benefit. Nevertheless, since our cohort of 5,000 MSM was very small (1\%) compared with the overall HIV-negative MSM population in England, and modest compared with the higher risk group of GUM attendees (29\%), the likely indirect impact of the PrEP programme would be limited. Recently, Nichols et al. quantified this indirect effect of a similarly modest PrEP intervention (average 4,500 MSM annually) delivered to a Dutch MSM population using a dynamic model and showed only a $13-16 \%$ change in the ICER when indirect effects were included [26]. Therefore, with a modest programme, the majority of benefits fall on those given PrEP. Should a very large PrEP programme be implemented, the long-term indirect effects would increase in dominance and a static modelling approach would be inappropriate.

In conclusion, whether or not PrEP drug is priced at a level that guarantees favourable cost effectiveness, reduced budgetary impact, and a shorter return on investment period, the analysis highlights other questions about PrEP scale-up that directly affect the financial considerations and the sustainability of any future programme. When proposed high-risk eligibility criteria are implemented, who and how many will access and take up PrEP? Will PrEP be taken up by those in whom PrEP is clinically recommended? What will be their level of adherence? What will be the effectiveness of regular clinical risk assessment at assuring that only those at continuing high-risk stay on PrEP to maintain cost-effectiveness and equitable access based on clinical need? These questions should be answered before embarking on a long-term PrEP-based intervention. A further clinical trial is proposed as a means to do this [31].

\section{Acknowledgements}

We thank Nick Andrews for statistical advice, Alison Brown, Zheng Yin and the HIV surveillance team at Public Health England for HIV surveillance data on time to diagnosis, treatment initiation, and $\mathrm{CD}_{4}+$ recovery, Valentina Cambiano, Alec Miners, and Andrew Phillips, for helpful comments on economic evaluation, Cuong Chau for distribution of HIV treatment regime and estimated numbers of HIV-positive diagnosis in year 2014/15, David Dolling for data from the UK PROUD trial, Kate Folkard, Patrick Lenehan, and Deborah Shaw for advice on commissioning and GUM tariff, Mark Jit for many helpful comments, Sheena McCormack and John Saunders for advice on care pathway for PrEP delivery via GUM clinics, Hamish Mohammed and the GUMCAD team for GUM clinic data, and Sonali Sonache for advice about HIV antiretroviral drugs.

\section{ROLE OF THE FUNDING SOURCE}

This work was part of core funding of the HIV and STI Department, CIDSC, Public Health England.

The funder had no role in study design; in the collection, analysis, and interpretation of data; in the writing of the report; and in the decision to submit the paper for publication.

The views expressed are those of the authors and not necessarily those of the Department of Health, the NHS, Local Authorities, or Public Health England.

\section{Conflict of interest}

None declared.

Authors' contributionsKJO, AJvH, and ONG designed the analysis and developed the methodology. SD performed analysis of genitourinary medicine clinic activity data and provided HIV incidence estimates. $\mathrm{KJO}, \mathrm{AJvH}$, and ONG analysed key data sources. KJO performed the cost-effectiveness and budget impact analysis, which was appraised by AJvH. KJO, AJvH, and ONG wrote the first draft of the manuscript and subsequent versions, with comments from SD, NF, MD, and AN. All authors approved the final version of the manuscript.

\section{References}

1. Public Health England (PHE). HIV in the UK Report [Internet]. London: PHE; 2016. Available from: https://www.gov.uk/government/ publications/hiv-in-the-united-kingdom

2. McCormack S, Dunn DT, Desai M, Dolling DI, Gafos M, Gilson R, et al. Pre-exposure prophylaxis to prevent the acquisition of HIV-1 infection (PROUD): effectiveness results from the pilot phase of a pragmatic openlabel randomised trial. Lancet. 2016;387(10013):53-60. https://doi. org/10.1016/S0140-6736(15)00056-2 PMID: 26364263

3. Grant RM, Lama JR, Anderson PL, McMahan V, Liu AY, Vargas L, et al. iPrEx Study Team. Preexposure chemoprophylaxis for HIV prevention in men who have sex with men. N Engl J Med. 2010;363(27):2587-99. https://doi.org/10.1056/NEJMoa1011205 PMID: 21091279

4. Molina J-M, Capitant C, Spire B, Pialoux G, Cotte L, Charreau I, et al. ANRS IPERGAY Study Group. On-Demand Preexposure Prophylaxis in Men at High Risk for HIV-1 Infection. N Engl J Med. 2015;373(23):2237-46. https://doi.org/10.1056/NEJMoa1506273 PMID: 26624850

5. National Health Service (NHS) England Specialised Services Clinical Reference Group for HIV. Clinical Commissioning Policy Proposition: Preexposure prophylaxis (PrEP) to prevent the acquisition of HIV in adults NHS England Fo3X06 Public Consultation. London: NHS; 2016. Available from: https://www.engage.england.nhs.uk/consultation/specialisedservices/user_uploads/fo3xo6-policy-proposition.pdf 
6. National Health Service (NHS) England. Commissioning Operations, Specialised Commissioning. Developing a method to assist investment decisions in specialised commissioning : next steps Consultation Guide [Internet]. London: NHS; 2016. Available from: https://www.engage. england.nhs.uk/consultation/investment-decisions/supporting documents/consultationguide.pdf

7. National Institute for Health and Care Excellence (NICE). Guide to the methods of technology appraisal 2013. London: NICE; 2013.

8. Joint Committee on Vaccination and Immunisation. Joint Committee on Vaccination and Immunisation - Code of Practice June 2013; 2013. [Accessed 17 Oct 2017]. Available from: https://www.gov.uk/ government/uploads/system/uploads/attachment_data/file/224864/ JCVI_Code_of_Practice_revision_2013_-_final.pdf

9. Pitman R, Fisman D, Zaric GS, Postma M, Kretzschmar M, Edmunds J, et al. ISPOR-SMDM Modeling Good Research Practices Task Force. Dynamic transmission modeling: a report of the ISPOR-SMDM Modeling Good Research Practices Task Force Working Group-5. Med Decis Making. 2012;32(5):712-21. https://doi.org/10.1177/0272989X12454578 PMID: 22990086

10. Molina J-M. Experience with the Implementation of PrEP in France. In: Fast-track the end of AIDS in the EU [Internet]. St Julians, Malta; 2017. Available from: https://www.slideshare.net/ECDC_EU/ experience-with-the-implementation-of-prep-in-france

11. Savage EJ, Mohammed H, Leong G, Duffell S, Hughes G. Improving surveillance of sexually transmitted infections using mandatory electronic clinical reporting: the genitourinary medicine clinic activity dataset, England, 2009 to 2013. Euro Surveill. 2014;19(48):20981. https://doi.org/10.2807/1560-7917.ES2014.19.48.20981 PMID: 25496573

12. London School of Hygiene and Tropical Medicine (LSHTM). Economic evaluation of HIV pre-exposure prophylaxis among men-who-have-sexwith-men in England in 2016. London: LSHTM; 2017. Available from: https://doi.org/10.17037/PUBS.04433707

13. European Medicines Agency (EMA). Truvada emtricitabine / tenofovir disoproxil [Internet]. Human medicines. London: EMA; 2016. [Accessed 19 Oct 2016]. Available from: http://www.ema.europa.eu/ema/index. jsp?curl=pages/medicines/human/medicines/ooo594/human med_001113.jsp\&mid=WCobo1ac058001d124

14. Desai S, Nardone A, Hughes G, Delpech V, Burns F, Hart G, et al. HIV incidence in an open national cohort of men who have sex with men attending sexually transmitted infection clinics in England. HIV Med. 2017;18(9):615-22. https://doi.org/10.1111/hiv.12498 PMID: 28127837

15. Mercer CH, Tanton C, Prah P, Erens B, Sonnenberg P, Clifton S, et al. Changes in sexual attitudes and lifestyles in Britain through the life course and over time: findings from the National Surveys of Sexual Attitudes and Lifestyles (Natsal). Lancet. 2013;382(9907):1781-94. https://doi.org/10.1016/S0140-6736(13)62035-8 PMID: 24286784

16. Office for National Statistics. ONS population estimates. ONS. Available from: https://www.ons.gov.uk/peoplepopulationandcommunity/ populationandmigration/populationestimates/datasets/ populationestimatesforukenglandandwalesscotlandandnorthernireland

17. Beck EJ, Mandalia S, Sangha R, Sharott P, Youle M, Baily G, et al. NPMS-HHC Steering Group. The cost-effectiveness of early access to HIV services and starting cART in the UK 1996-2008. PLoS One. 2011;6(12):e27830. https://doi.org/10.1371/journal.pone.0027830 PMID: 22194795

18. Public Health England (PHE). HIV surveillance systems. London: PHE. Available from: https://www.gov.uk/hiv-surveillance-systems

19. National Health Service (NHS) England Specialised Commissioning Team. Clinical Commissioning Policy : Treatment as Prevention (TasP) in HIV infected adults. London: NHS; 2015. p. 1-24. Available from: https://www.england.nhs.uk/commissioning/wp-content/uploads/ sites/12/2015/10/fo3pc-tasp-oct15.pdf

20. National Health Service (NHS) England. Freedom of Information request (Ref: FOl-007334). London: NHS; 2015.

21. Curtis L. Unit Costs of Health \& Social Care 2014. Canterbury: Personal Social Services Research Unit; 2014.

22. Marcus JL, Hurley LB, Hare CB, Nguyen DP, Phengrasamy T, Silverberg M), et al. Preexposure Prophylaxis for HIV Prevention in a Large Integrated Health-Care System: Adherence, Renal Safety, and Discontinuation. J Acquir Immune Defic Syndr. 2016;73(5):540-6. https:// doi.org/10.1097/QAl.0000000000001129 PMID: 27851714

23. Aghaizu A, Wayal S, Nardone A, Parsons V, Copas A, Mercey D, et al. Sexual behaviours, HIV testing, and the proportion of men at risk of transmitting and acquiring HIV in London, UK, 2000-13: a serial crosssectional study. Lancet HIV. 2016;3(9):e431-40. https://doi.org/10.1016/ S2352-3018(16)30037-6 PMID: 27562744

24. Revicki DA, Frank L. Pharmacoeconomic evaluation in the real world. Effectiveness versus efficacy studies. Pharmacoeconomics. 1999;15(5):423-34. https://doi.org/10.2165/00019053-19991505000001 PMID: 10537960

25. Alaei K, Paynter CA, Juan S-C, Alaei A. Using preexposure prophylaxis, losing condoms? Preexposure prophylaxis promotion may undermine safe sex. AIDS. 2016;30(18):2753-6. https://doi.org/10.1097/ QAD.0000000000001262 PMID: 27824624
26. Nichols BE, Boucher CAB, van der Valk M, Rijnders BJA, van de Vijver DAMC. Cost-effectiveness analysis of pre-exposure prophylaxis for HIV-1 prevention in the Netherlands: a mathematical modelling study. Lancet Infect Dis. 2016;16(12):1423-9. https://doi.org/10.1016/S14733099(16)30311-5 PMID: 27665989

27. Ouellet E, Durand M, Guertin JR, LeLorier J, Tremblay CL. Cost effectiveness of 'on demand' HIV pre-exposure prophylaxis for non-injection drug-using men who have sex with men in Canada. Can J Infect Dis Med Microbiol. 2015;26(1):23-9. https://doi. org/10.1155/2015/964512 PMID: 25798150

28. Schneider K, Gray RT, Wilson DP. A cost-effectiveness analysis of HIV preexposure prophylaxis for men who have sex with men in Australia. Clin Infect Dis. 2014;58(7):1027-34. https://doi.org/10.1093/cid/cit946 PMID: 24385445

29. Chen A, Dowdy DW. Clinical effectiveness and cost-effectiveness of HIV pre-exposure prophylaxis in men who have sex with men: risk calculators for real-world decision-making. PLoS One. 2014;9(10):e108742. https://doi.org/10.1371/journal.pone.0108742 PMID: 25285793

30. Birrell PJ, Gill ON, Delpech VC, Brown AE, Desai S, Chadborn TR, et al. HIV incidence in men who have sex with men in England and Wales 200110: a nationwide population study. Lancet Infect Dis. 2013;13(4):313-8. https://doi.org/10.1016/S1473-3099(12)70341-9 PMID: 23375420

31. National Health Service (NHS) England. NHS England announces major extension of national HIV prevention programme with Public Health England and funding for ten new specialised treatments [Internet]. News. London: NHS; 2016 [4 Dec 2016]. Available from: https://www.england. nhs.uk/2016/12/hiv-prevention-pregramme/

32. British Medical Association, Royal Pharmaceutical Society. British National Formulary. 7oth ed. London: Published jointly by BMJ Group and Pharmaceutical Press; 2015. p1366.

33. Pathway Analytics. Integrated Sexual Health Tariff. Available from: http://sexualhealthtariff.pathwayanalytics.com/

34. Miners A, Phillips A, Kreif N, Rodger A, Speakman A, Fisher M, et al. ASTRA (Antiretrovirals, Sexual Transmission and Attitudes) Study. Health-related quality-of-life of people with HIV in the era of combination antiretroviral treatment: a cross-sectional comparison with the general population. Lancet HIV. 2014;1(1):e32-40. https://doi.org/10.1016/S23523018(14)70018-9 PMID: 26423814

35. Kind P, Hardman G, Macran S. EQ5D UK population norms. York: The University of York; 1999. p98.

36. Sciences G. United States Securities and Exchange Commission 2015 Form 10-K Annual Report pursuant to Section 13 or 15(d) of the Securities Exchange Act of 1934 for the fiscal year ended December 31, 2015. Gilead Sciences. Delaware; 2015. Available from: http://www.gilead.com/ ar2015/assets/img/GileadSciences_10K_20160224.pdf

37. Churchill D, Waters L, Ahmed N, Angus B, Boffito M, Bower M, et al. British HIV Association guidelines for the treatment of HIV-1- positive adults with antiretroviral therapy, 2015. London: BHIVA;Jul 2012:p1-114. Available from: http://www.bhiva.org/documents/Guidelines/ Treatment/2015/2015-treatment-guidelines.pdf

38. Nakagawa F, Lodwick RK, Smith CJ, Smith R, Cambiano V, Lundgren JD, et al. Projected life expectancy of people with HIV according to timing of diagnosis. AIDS. 2012;26(3):335-43. https://doi.org/10.1097/ QAD.obo13e32834dcec9 PMID: 22089374

39. National Institute for Health and Care Excellence (NICE). Pre-exposure prophylaxis of HIV in adults at high risk: Truvada (emtricitabine/ tenofovir disoproxil). Evidence summary: new medicine [ESNM78]; 2016. [Accessed 27 Oct 2016]. p. 1-50. Available from: https://www.nice.org. uk/advice/esnm78/chapter/Full-evidence-summary

\section{License and copyright}

This is an open-access article distributed under the terms of the Creative Commons Attribution (CC BY 4.0) Licence. You may share and adapt the material, but must give appropriate credit to the source, provide a link to the licence, and indicate if changes were made.

This article is copyright of the authors, 2017. 